\title{
More then 10 years as Editor-in-Chief of Neurological Sciences: greetings and acknowledgements
}

\author{
Antonio Federico ${ }^{1}$ \\ Published online: 27 November 2021 \\ (c) Fondazione Società Italiana di Neurologia 2021
}

The December 2021 issue of Neurological Sciences is the last one I am editing as Editor-in-Chief of the journal, after more than 10 years of service in this position.

Both the journal and I have come a long way together, with successes and disappointments, I myself growing in age and experience, and the journal in international reputation. It was not an easy job, but with the support of the Italian Society of Neurology, the Associate Editors, the Editorial Board, and Springer, we were able to transform a national journal of the Italian Society of Neurology into an international one, in the rich panorama of the clinical neurosciences.

We enlarged the Associate Editor group with distinguished neuroscientists from many different countries: I thank them very much for their contribution to the development of the journal.

We recently introduced Topical collections, covering important and emerging areas of neurology such as "Autonomic nervous system in clinical practice" edited by Prof. Hilz, "Eye movements in general neurology and its subspecialties" edited by Prof. Zee, and "The growing role for neurology in neuro-oncology" edited by Prof. Grisold. I very much acknowledge them for their efforts and enthusiasm.

Figure 1 shows the main changes in the editorial development performance: we observed a linear increase in the submitted articles, from 900 in 2012 to more than 2400 in 2020, and similar numbers for this year. The manuscripts were submitted by neurologists from all over the world, many from China and other Eastern countries, with an acceptance rate of $25-30 \%$.

Full-text article downloads, which numbered a little over 220,000 in 2012, grew to more than 570,000 in 2020, and

Antonio Federico

antonio.federico@unisi.it

1 Department Medicine, Surgery and Neurosciences, Medical School, University of Siena, Viale Bracci 2, 53100 Siena, Italy in September 2021 they had reached more than 700,000 (Fig. 2).

A similar constant increase in the impact factor was observed, from 1.3 in 2011 to 3.3 in 2020 (Fig. 3).

Serving as Editor-in-Chief is not an easy job.

I report here two examples of difficulties we met. The first one was related to the discovery of fabricated peerreview reports. The fraud affected many journals and led to retraction of several articles, but we were one of the first to discover it. The investigation focused on articles for which authors had suggested their own reviewers. The second example is more recent, and it was related to the need, after the emergence and spread of the COVID-19 pandemic, to speed up the peer-review process of the numerous articles we received on the topic, in order to publish the data as soon as possible to improve the diagnosis and care of this disorder. It was a big effort, with fast publication of the best articles on COVID in each issue of the journal.

In these 10 years, I have read and given feedback on thousands of manuscripts from authors around the world and have worked with an outstanding editorial team, Editorial Board, and colleagues serving as reviewers. To all of them, I pay tribute to their constancy and efforts to make our journal into the journal it is now, with a rising journal ranking and impact factor. Today INR's impact factor is 3.3.

These results have been obtained through consistent application and a unique attitude in selecting the best papers that may be of general neurological interest, leading to increased knowledge in the scientific community, also evidenced by the increase in citations, representative of the quality of the selected articles. I know that I disappointed many people with the rejection of their articles, but for others, with the help of the reviewers who voluntary evaluated them, the authors have often been helped in improving their manuscripts, with final acceptance and possible quotation as reference by other neurologists.

In fact, as University Professor, I regarded my mission of Editor-in-Chief as an educational activity as well, 


\section{Editorial development}

Submissions/Acceptances

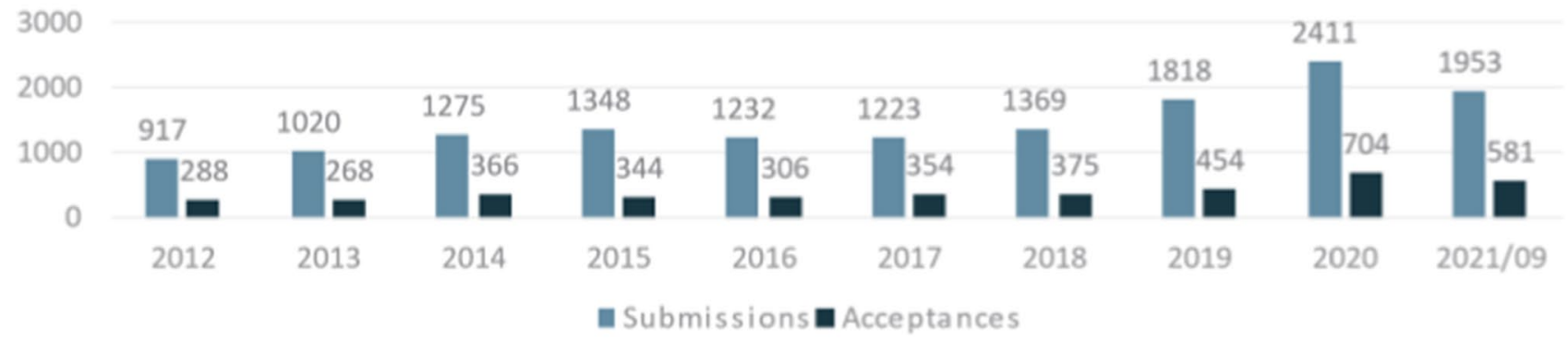

\section{Turnaround times}

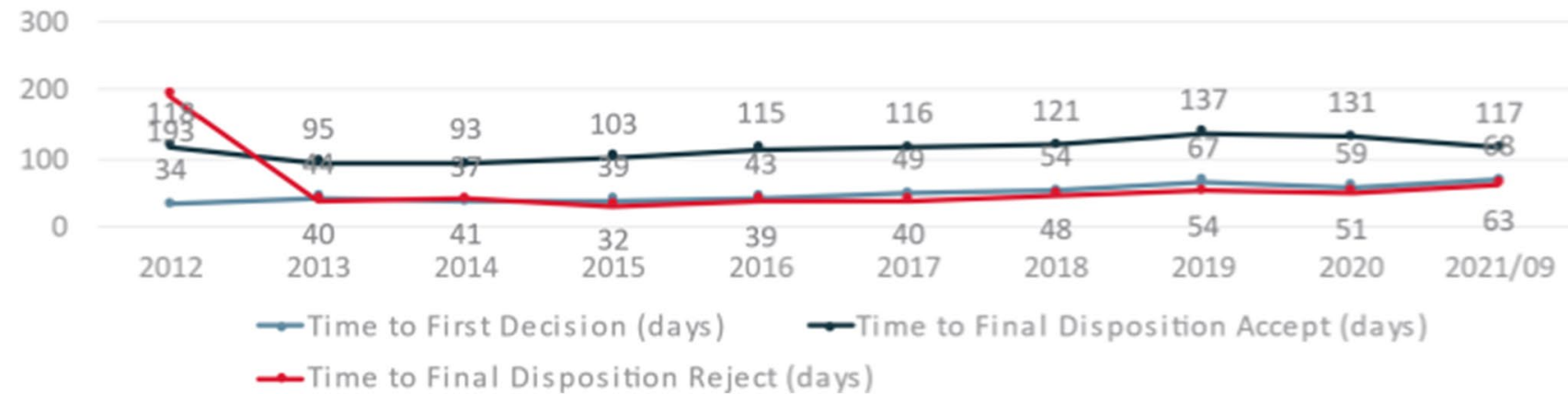

Fig. 1 Editorial development during the last 10 years (submission and acceptance and turnaround times)

Fig. 2 The increase in full-text downloads during the last 10 years

\section{Usage}

Full-Text Article Downloads

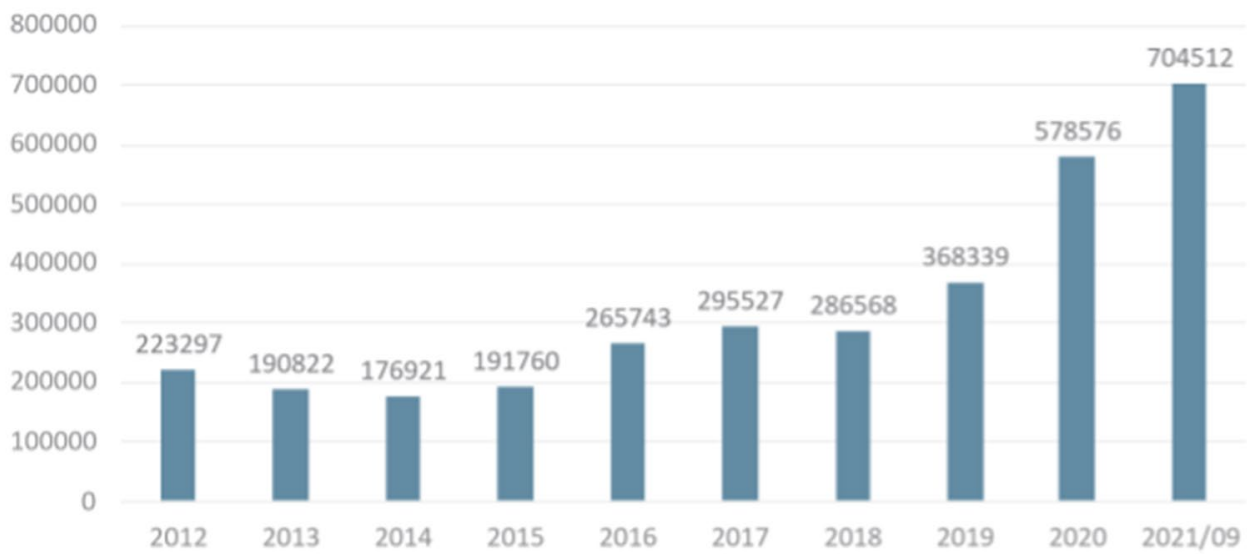

mainly for young generations, giving suggestions on how to improve their capacity to correctly report good scientific results. Our goals have been firstly to recognize good scientific results and then to help the authors improve the quality of the manuscripts.

The new Editor-in-Chief, Dr. F. Tagliavini, a well-known neuroscientist and expert in neurodegenerative diseases and 


\section{Impact Factor}

\section{2-year Impact Factor}

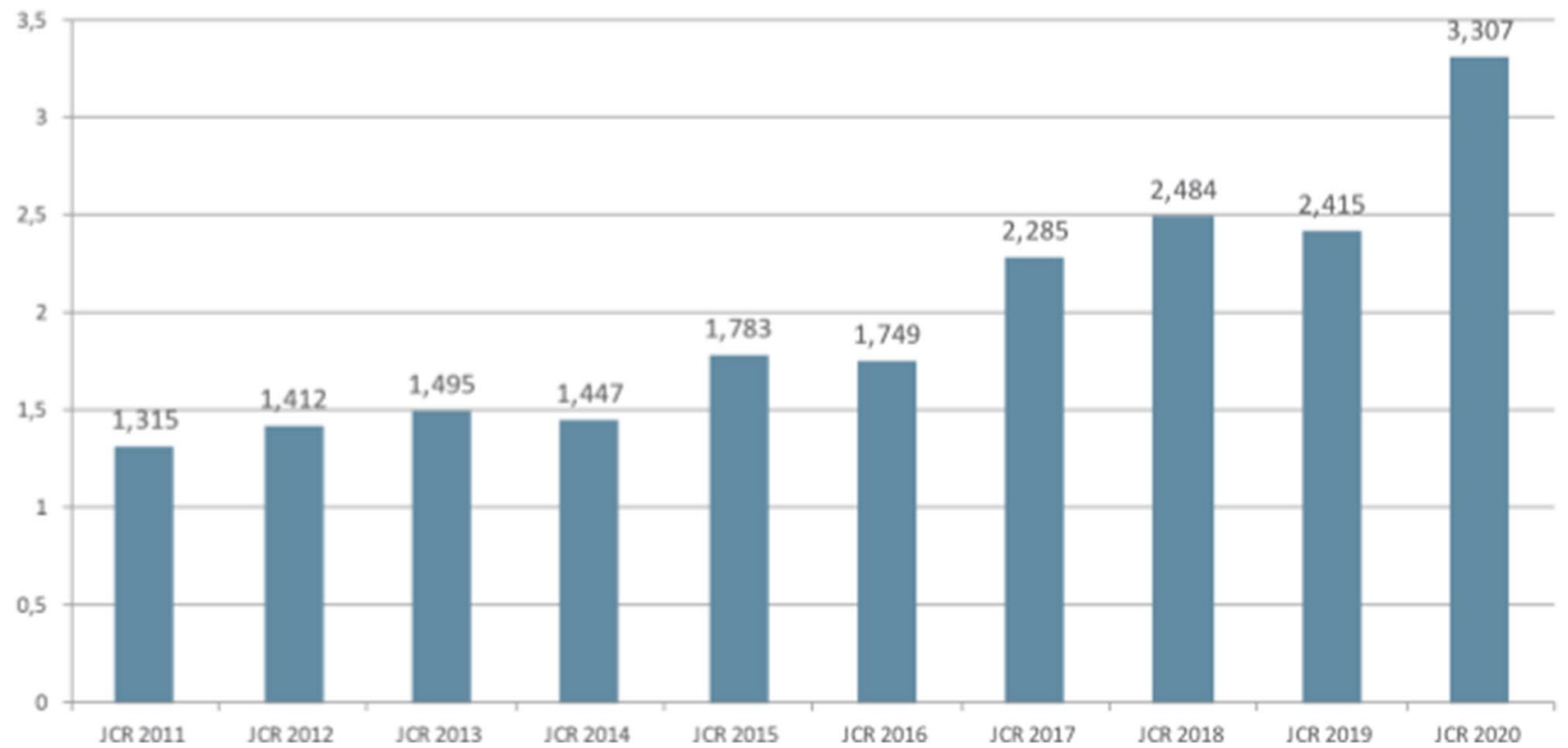

Fig. 3 Linear increase in the impact factor

neuropathology, is also the former scientific director of the Istituto Neurologico C. Besta, Milan, where this journal was born, founded by Prof. R. Boeri, and later directed by Prof. Avanzini, before me. To him, my best wishes for this new appointment that I am sure will be successful.

I need to express my deep gratitude to my direct collaborators in the Editorial staff: Giovanna Castelli, who has served as Editorial Secretary of the journal since the beginning with exceptional dedication and precision, to Dr. Ilaria Taglia, and the two Springer collaborators, Drs. Barbara Pedrotti and Patrizia Bianchi, who throughout the years have supported us in keeping the rudder in the right direction from the editorial point of view.

Finally, thanks to all neurologists who submitted manuscripts to this journal and to all our readers.

\section{Declarations}

Ethical approval None.

Conflict of Interest None.

Author disclosures No disclosures.

Publisher's note Springer Nature remains neutral with regard to jurisdictional claims in published maps and institutional affiliations. 